\title{
A study on maternal and perinatal outcome of oligohydramnios in term low risk pregnancy
}

\author{
Sripreethika Rajavelu $^{1 *}$, Vinitra Dayalan ${ }^{1}$, Surya S. $^{2}$
}

\begin{abstract}
${ }^{1}$ Department of Obstetrics and Gynecology, Government Chengalpattu Medical College, Tamil Nadu, India
${ }^{2}$ Department of Obstetrics and Gynaecology, Government Omandurar Medical College, Tamilnadu, India
\end{abstract}

Received: 01 September 2019

Accepted: 01 October 2019

\author{
*Correspondence: \\ Dr. Sripreethika Rajavelu, \\ E-mail: sripreethika.academic@gmail.com
}

Copyright: () the author(s), publisher and licensee Medip Academy. This is an open-access article distributed under the terms of the Creative Commons Attribution Non-Commercial License, which permits unrestricted non-commercial use, distribution, and reproduction in any medium, provided the original work is properly cited.

\begin{abstract}
Background: Oligohydramnios is a frequent complication of pregnancy that is associated with increased perinatal morbidity and mortality. Once diagnosed; oligohydramnios should further lead to intensive fetal surveillance including ultrasound evaluation. The aim of the study was to determine obstetric outcome in term low risk pregnancy with AFI less than or equal to 5 and to assess whether antepartum oligohydramnios is associated with adverse perinatal outcome.

Methods: 200 patients in third trimester in the hospital with evidence of oligohydramnios (AFI less than or equal to 5) were selected after satisfying inclusion and exclusion criteria and studied prospectively. Observations regarding the outcome of labour in form of maternal and perinatal parameters including AFI value, CTG features, mode of delivery, LSCS rate, meconium stained, APGAR score, birth weight and NICU admission were made.

Results: Overall perinatal outcome with respect to CTG, $128(64 \%)$ out of 200 patients had non-reactive CTG and only 72 (36\%) had reactive CTG. 128 (64\%) of non-reactive CTG delivered by LSCS, 72 (36\%) delivered by labour natural. Nil labour natural in the subset of AFI 1 to 2, birth weight ( $<2.5 \mathrm{~kg}-8 \%$ and $>2.5 \mathrm{~kg}-92 \%)$, Apgar score $(<7$ at 1-5 mins: $18 \%)$, still birth (1\%), meconium (58.5\%), NICU admission (6\%) and perinatal mortality $(2 \%)$.

Conclusions: AFI measurement of less than $5 \mathrm{~cm}$ detected after 37 completed weeks of gestation with a low risk pregnancy is found to be an indicator of adverse pregnancy outcome with higher fetal distress, meconium stained liquor and higher caesarean section rate. AFI assessment serves as an important tool and remains as an effective screening test in predicting fetal distress in labour that requires caesarean section.
\end{abstract}

Keywords: Amniotic fluid less than 5, Fetal distress, Maternal outcome, Meconium, Oligohydramnios, Perinatal outcome, Pregnancy

\section{INTRODUCTION}

Amniotic fluid is a clear, yellowish coloured fluid contained in amniotic sac which is in circulation around the fetus. It has numerous functions which are important for the fetus and its development in-utero. ${ }^{1,2}$ Amniotic fluid is regulated primarily by fetal swallowing and this has been observed as early in 16 weeks. The fluid gets absorbed through fetal gastrointestinal system and it either gets transferred to the maternal circulation or gets recycled back through the kidney. Amniotic fluid volume, a perfectly regulated process is dependent on the respective gestational age, and it is maintained within a specific fixed range. The amniotic fluid peaks between 34-36 weeks of about $800-1000 \mathrm{ml}$ and therefore declines to about $400 \mathrm{ml}$ at 42 week. $^{3}$ Amniotic fluid volume measuring less than $500 \mathrm{ml}$ at 32 to 36 weeks of gestation is oligohydramnios. Amniotic fluid volume depends mainly on the gestational age; therefore, the best definition could be the one that is less than fifth percentile. Oligohydramnios is defined by USG as an amniotic fluid index $5 \mathrm{~cm}$ or less or Single deepest pocket 
(SDP) of amniotic fluid value less than $2 \mathrm{~cm}$ is oligohydramnios. Incidence of oligohydramnios are varied from $0.5 \%$ to $5 \%$.

There are no specific symptoms. Some of the pointers may be history of leaking per vaginum, post term pregnancy, preeclampsia, drugs and less perception of fetal movements. On clinical examination the uterus may be small for date i.e. smaller symphysis-fundal height and feels full of fetus because of scanty amniotic fluid. Oligohydramnios in third trimester, is predominantly due to PROM. ${ }^{4}$ As development of lung and limbs require adequate amniotic fluid. Oligohydramnios is found to be associated with lot of complications which include.

\section{Fetal}

Prematurity, abortion, IUFD, Potters syndrome, deformities (CTEV, contractures, amputation), malpresentations, fetal distress, meconium stained amniotic fluid, low APGAR, Cord compression and Amnion nodosum. ${ }^{5,6}$

\section{METHODS}

\section{Maternal}

Prolonged labour-dystocia and uterine inertia, increased operative interference and increased morbidity. Management for oligohydramnios depends on aetiology, gestational age, severity and fetal status and well-being. Treatment includes rest, oral or IV hydration and serial USG assessment. ${ }^{7}$ Ultrasound measurement of amniotic fluid can be assessed either as subjective assessment or as a semi quantitative method. Semi-quantitative methods include single maximal vertical pocket (SVP), the twodiameter pocket technique and the amniotic fluid index (AFI). ${ }^{8,9}$ This study involves observing Obstetric outcome in term low risk pregnancy with AFI less than or equal to 5 and to assess whether antepartum oligohydramnios is associated with adverse perinatal outcome.

This was a prospective study conducted at Government Chengalpattu Medical College in Department of Obstetrics and Gynaecology over period from August 2017 to July 2018. 200 patients in third trimester attending the hospital with evidence of Oligohydramnios were selected after satisfying inclusion and exclusion criteria. Written informed consent was taken from the patients.

\section{Inclusion criteria}

- AFI less than or equal to 5

- Single live intrauterine gestation with cephalic presentation

- 37 completed weeks of gestation

- Intact membranes.

\section{Exclusion criteria}

- Gestational age less than 37 completed weeks

- AFI more than 5

- Post term.

- Associated fetal malformations.

- Malpresentation and multiple gestations.

- Ruptured membranes

- High risk pregnancy

a) Placental insufficiency

i. Hypertension

ii. Preeclampsia

iii. Diabetes

iv. Chronic renal disease

v. Hypovolemia

vi. Connective tissue disorders.

b) Abruption

c) Angiotensin converting enzyme inhibitors therapy

- Uterine scar due to Previous LSCS, myomectomy, hysterectomy.

This study was conducted in order to observe outcome of labour in the form of maternal and perinatal outcome. After collecting a detailed history, complete examination was done. All required investigations performed with respect to patient's condition. Oligohydramnios is confirmed by measuring Amniotic Fluid Index by USG. ${ }^{10}$ Routine management in form of rest, oral and intravenous hydration, left lateral position and control of etiological factor was done if present. Fetal surveillance was done by means of modified Biophysical profile and USG. Decision of delivery by induction or elective or emergency LSCS was done as indicated some patients who were already in labour were allowed to go in spontaneous labour. Cases were than thoroughly studied to observe maternal and perinatal outcome. Parameters like distribution by AFI, mode of delivery with respect to AFI, CTG profile of patients, mode of delivery with respect to $\mathrm{CTG}$, mode of delivery with respect to meconium, distribution according to birth weight, incidence of still birth, NICU admission, and perinatal outcome are studied.

\section{Statistical analysis}

Data were analysed using the Statistical Package for Social Sciences (SPSS) version 13.0.1 Means, standard deviations and simple percentage were determined. Chisquare value was used for significance level. $\mathrm{P}<0.05$ was considered significant using the Pearson's $\mathrm{x} 2$ test.

\section{RESULTS}

A total of 200 women attending to the institution got admitted and studied in the study period. The abovementioned parameters are studied. 
Table 1 shows that $94 \%$ of the study population had an Amniotic fluid index of 4 to $5 \mathrm{~cm}$ and $6 \%$ with AFI 1 to $3 \mathrm{~cm}$ (Table 1).

Table 1: Distribution by AFI (USG).

\begin{tabular}{|lll|}
\hline AFI & Frequency & Percentage (\%) \\
\hline 1 to 3 & 12 & 6 \\
\hline 4 to 5 & 188 & 94 \\
\hline Total & $\mathbf{1 0 0}$ & \\
\hline
\end{tabular}

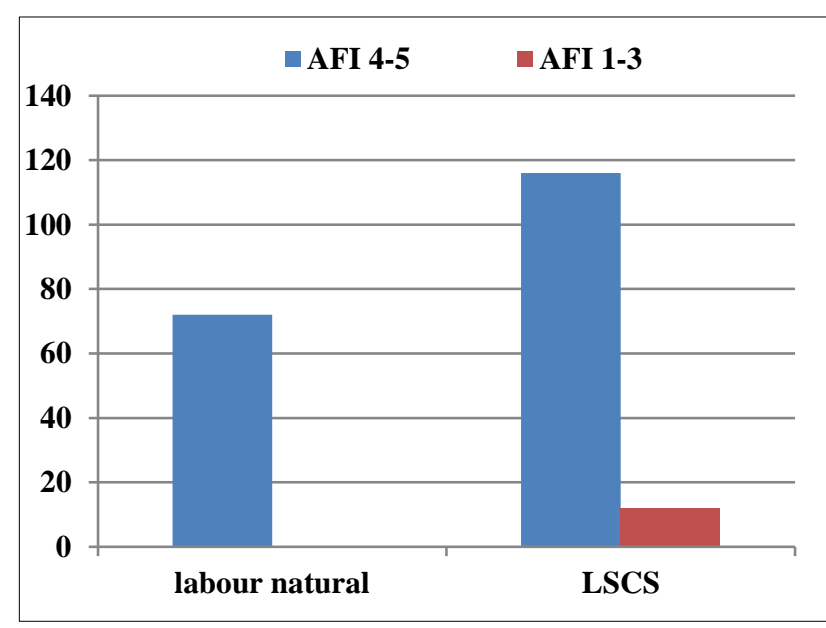

Figure 1: Mode of delivery with respect to AFI.

This table shows that there was nil labour natural in the subset of AFI 1 to 2 in the study population and caesarean section rate was higher in this group (Figure 1).

Table 2: CTG and mode of delivery with respect to CTG.

\begin{tabular}{|lllll|}
\hline CTG & Number & $\begin{array}{l}\text { Percentage } \\
(\%)\end{array}$ & $\begin{array}{l}\text { Mod } \\
\text { LN }\end{array}$ & $\begin{array}{l}\text { Mod } \\
\text { LSCS }\end{array}$ \\
\hline Reactive & 72 & 36 & 71 & 47 \\
\hline Non-reactive & 128 & 64 & 1 & 81 \\
\hline P value: 0.001 & & & & \\
\hline
\end{tabular}

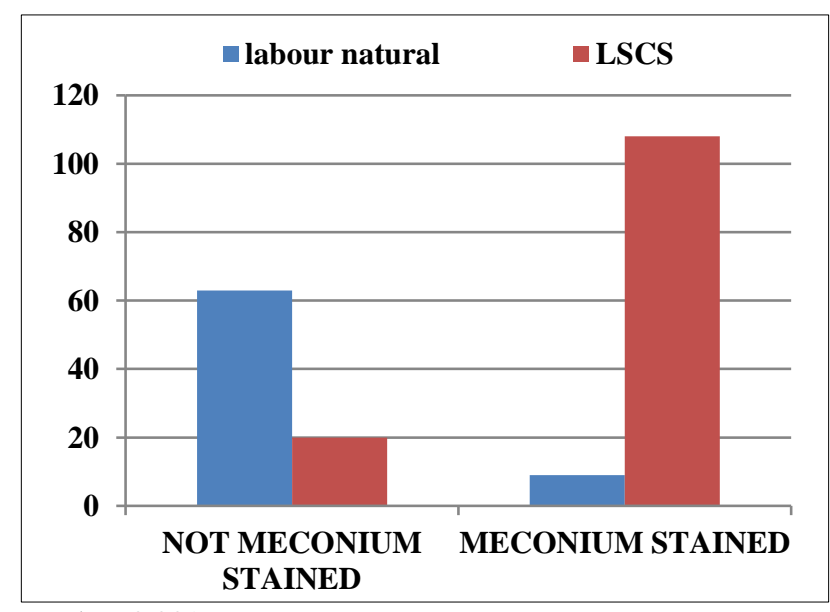

$P$ value: 0.001 .

Figure 2: Mode of delivery with respect to meconium.
On observation, 128 (64\%) out of 200 patients had nonreactive CTG and only 72 (36\%) had reactive CTG. This table shows that the rate of cesarean section was higher among non-reactive CTG group. Its p value is (0.001) and it is statistically significant. Operative morbidity was more in non-reactive CTG group (Table 2).

Overall meconium stained amniotic fluid occurred in $58.5 \%$ of the study population. Of which $36 \%$ had labour natural and $64 \%$ had cesarean section. It was statistically significant (p value <0.001) (Figure 2).

Table 3: Perinatal outcome.

\begin{tabular}{|lll|}
\hline Disease & Number & Percentage $(\%)$ \\
\hline Birth weight & & \\
\hline$<2.5 \mathrm{~kg}$ & 16 & 8 \\
\hline$>2.5 \mathrm{~kg}$ & 184 & 92 \\
\hline Apgar score & & \\
\hline$<7$ at 1 to 5 mins & 36 & 18 \\
\hline Still birth & 2 & 1 \\
\hline Meconium & 117 & 58.5 \\
\hline NICU admission & 12 & 6 \\
\hline perinatal mortality & 4 & 2 \\
\hline
\end{tabular}

The table shows the overall perinatal outcome with respect to birth weight $(<2.5 \mathrm{~kg}-8 \%$ and $>2.5 \mathrm{~kg}-92 \%)$, Apgar score ( $<7$ at $1-5$ mins:18\%), still birth (1\%), meconium $(58.5 \%)$, NICU admission $(6 \%)$ and perinatal mortality (2\%) (Table 3).

\section{DISCUSSION}

It is a known fact that severe oligohydramnios is associated with adverse perinatal outcome. Oligohydramnios is commonly encountered and it necessitates extensive fetal surveillance and perfect antepartum and intrapartum care. Amniotic fluid volume is an important predictor of fetal level of tolerance during labour and its decrease is associated with increased risk of fetal distress and meconium staining of fluid. Due to unforeseen intrapartum complication and high incidence of perinatal mortality and morbidity, caesarean section rates are on the rise, but the decision between caesarean section and vaginal delivery must be well balanced so that unnecessary maternal morbidity could be prevented and timely decision can reduce perinatal mortality and morbidity. But often oligohydramnios is used as an indication for operative delivery. Hence assessing amniotic fluid volume antenatal is essential in determining high and low risk groups.

The present study revealed that, cesarean section rate was higher among non-reactive CTG group. This goes with the study by Jandial C whish stated a non-reactive CTG + AFI $<5 \mathrm{~cm}$ indicated fetal jeopardy according to revised Biophysical profile scoring. ${ }^{11}$ The fetal jeopardy reflected an increased operative interference in this study. 
This study showed high incidence of meconium stained liquor $(58.5 \%)$ in oligohydramnios patient with $\mathrm{AFI}<5$ $\mathrm{cm}$. Meconium staining is an indicator of fetal distress and has its own complication in new-born. This goes with the study by Jandial I et al, which observed meconium stained liquor in $48 \%$ of women with oligohydramnios.

The rate of NICU admission was found to be $6 \%$, of which perinatal mortality was $2 \%$. In the study done by Wolff-F, $17 \%$ of new-born were referred to nearby paediatric hospital immediately following delivery. This difference may be due to the facilities encountered in the hospital set up.

\section{CONCLUSION}

To conclude, an AFI measurement of less than $5 \mathrm{~cm}$ detected after 37 completed weeks of gestation with a low risk pregnancy is found to be an indicator of adverse pregnancy outcome with higher cesarean section rate. In our study, in presence of AFI $<5 \mathrm{~cm}$, the occurrence of non-reactive CTG, incidence of meconium stained liquor and rate of LSCS are high. Hence AFI assessment serves as an important tool and remains as an effective screening test in predicting fetal distress in labour that requires cesarean section.

\section{ACKNOWLEDGMENTS}

Authors would like to thank Dr. G. Mannar Mannan M. S., general surgery, for his esteemed help in publishing this article.

\section{Funding: No funding sources}

Conflict of interest: None declared

Ethical approval: The study was approved by the Institutional Ethics Committee

\section{REFERENCES}

1. A Underwood, Mark and M Gilbert, William and Sherman, Michael. Amniotic Fluid: Not Just Fetal Urine Anymore. J Perinatol official journal of the California Perinatal Association. 2005;25:341-8.

2. Physiology of amniotic fluid volume regulation. Brace RA Clin Obstet Gynecol. 1997;40(2):280.

3. Brace RA, Wolf EJ. Normal amniotic fluid volume changes throughout pregnancy. Am J Obstet Gynecol. 1989;161:382-8.
4. Van Reempts P, Kegelaers B, Van Dam K, Van Overmeire B. Neonatal outcome after very prolonged rupture of membranes. Am J Perinatol. 1993;10:288-91.

5. Hill LM, Breckle R, Wolfgram KR, O'Brien PC. Oligohydramnios: ultrasonically detected incidence and subsequent fetal outcome. Am J Obstet Gynecol. 1983;147(4):407-10.

6. Mercer LG, Brown LG. Fetal outcome with oligohydramnios in the second trimester. Obstet Gynecol. 1986;67(6):840-2.

7. Bastide A, Manning F, Harman G, Lange I, Marrison I. Ultrasound evaluation of amniotic fluid: outcome of pregnancy with severe oligohydramnios. Am J Obstet Gynecol. 1986;15(4):895-900.

8. Reddy UM, Abuhamad AZ, Levine D. Fetal imaging: executive summary of a joint Eunice Kennedy Shriver National Institute of Child Health and Human Development, Society for Maternal-Fetal Medicine, American Institute of Ultrasound in Medicine, American College of Obstetricians and Gynecologists, American College of Radiology, Society for Pediatric Radiology, and Society of Radiologists in Ultrasound Fetal Imaging workshop. Obstet Gynecol. 2014;123:1070.

9. Magann EF, Chauhan SP, Hitt WC. Borderline or marginal amniotic fluid index and peripartum outcomes: a review of the literature. J Ultrasound Med. 2011;30:523.

10. Youssef AA, Abdulla SA, Sayed EH, Salem HT, Abdelalim AM, Devoe LD. Superiority of amniotic fluid index over amniotic fluid pocket measurement for predicting bad fetal outcome. South Med J. 1993;86(4):426-9.

11. Jandial C, Gupta S, Sharma S, Gupta M. Perinatal Outcome after Antepartum Diagnosis of Oligohydramnios at or Beyond 34 Weeks of Gestation. JK Sci. J Med Edu Res. 2007;9(4):213-4.

Cite this article as: Rajavelu S, Dayalan V, Surya S. A study on maternal and perinatal outcome of oligohydramnios in term low risk pregnancy. Int $\mathbf{J}$ Reprod Contracept Obstet Gynecol 2019;8:4346-9. 